Article

\title{
Electrocatalytic Oxidation of Small Molecule Alcohols over Pt, Pd, and Au Catalysts: The Effect of Alcohol's Hydrogen Bond Donation Ability and Molecular Structure Properties
}

\author{
Bei Wang ${ }^{1,+}$, Liu Tao ${ }^{1,+}$, Yu Cheng ${ }^{1}$, Fang Yang ${ }^{1}$, Yuguang Jin ${ }^{1}$, Chunmei Zhou ${ }^{1, *}$, Hao Yu ${ }^{2, *}$ \\ and Yanhui Yang ${ }^{1}$ D \\ 1 School of Chemistry and Molecular Engineering (SCME), Institute of Advanced Synergetic Innovation \\ Center for Advanced Synthesis (IAS), The Synergetic Innovation Center for Advanced Materials (SICAM), \\ Nanjing Tech University, Nanjing 211816, China; murphywb@163.com (B.W.); tll1370635798@163.com (L.T.); \\ ycheng1012@163.com (Y.C.); skyfyang@163.com (F.Y.); jinyuguan@163.com (Y.J.); \\ yhyang@njtech.edu.cn (Y.Y.) \\ 2 The School of Chemistry and Chemical Engineering, South China University of Technology, \\ Guangzhou 510640, China \\ * Correspondence: ias_cmzhou@njtech.edu.cn (C.Z.); yuhao@scut.edu.cn (H.Y.); \\ Tel.: +86-2558-13-0047 (C.Z.); +86-2087-11-4916 (H.Y.) \\ $+\quad$ Liu Tao and Bei Wang contributed equally to this work.
}

Received: 1 March 2019; Accepted: 16 April 2019; Published: 25 April 2019

\begin{abstract}
The direct alcohol fuel cell is a kind of power generation device that directly converts the chemical energy of small molecule alcohols into electric energy. In this paper, the electro-oxidation behaviors of some typical alcohols (methanol, ethanol, ethylene glycol, n-propanol, 2-propanol, and glycerol) over $\mathrm{Pt}, \mathrm{Pd}$, and $\mathrm{Au}$ electrodes were investigated in acidic, neutral, and alkaline media, respectively. By analyzing the activity information from a cyclic voltammetry $(\mathrm{CV})$ method and some dynamic tests, several regularities were revealed in those electro-oxidation behaviors. Firstly, alkaline media is the best for the electro-oxidation of all these alcohols over $\mathrm{Pt}, \mathrm{Pd}$, and $\mathrm{Au}$ catalysts. Secondly, the hydrogen bond donation abilities (HBD) of different alcohols were found have a great relationship with the catalytic performance. In alkaline media, on Pt electrodes, the solute HBD is positively correlated with the ease of electrooxidation within the scope of this experiment. Contrarily, it is negatively correlated on Pd and Au electrodes. Additionally, for Pt catalysts in acidic and neutral media, the relationship becomes negative again as the HBD increases. Finally, the alcohol's molecular structure properties were found to have a remarkably influence on the activity of different catalysts. Over the Pt electrode in alkaline media, the activation energy of methanol oxidation is $44.1 \mathrm{KJ} / \mathrm{mol}$, and is obviously lower than the oxidation of other alcohols. Under similar conditions, the lowest activation energy was measured in the oxidation of n-propanol $(14.4 \mathrm{KJ} / \mathrm{mol})$ over the Pd electrode, and in the oxidation of glycerol $(42.2 \mathrm{KJ} / \mathrm{mol})$ over the Au electrode. Totally, among all these electrodes, Pt electrodes showed the best activities on the oxidation of $\mathrm{C} 1$ alcohol, $\mathrm{Pd}$ electrodes were more active on the oxidation of C2-3 monobasic alcohols, and Au electrodes were more active on the oxidation of polybasic alcohols.
\end{abstract}

Keywords: DAFCs; electro-oxidation; gold; palladium; platinum

\section{Introduction}

Direct alcohol fuel cells (DAFCs) generate electric power by feeding liquid fuels directly to the anode, which have been recognized as green energy generators capable of converting renewable sources 
into electric power [1,2]. The thermodynamic efficiency of a DAFC is $>90 \%$ because energy from the fuel is directly transformed into electric energy without the constraints of Carnot's theorem $[3,4]$. There have also been recent studies that found that DAFCs selectively produce high-value products while obtaining electric energy $[5,6]$.

So far, $\mathrm{Pt}, \mathrm{Pd}$, and $\mathrm{Au}$ catalysts are thought to be the most mature and efficient anode catalysts for DAFCs. Especially, Pt-based electrocatalysts are considered to be the best alcohol oxidation catalysts at low temperatures [7-9]. However, due to the high cost and limited resources of $\mathrm{Pt}$, it is necessary to increase its activity and utilization rate. On the one hand, to increase dispersion, Pt nanoparticles are prepared and loaded on carbon materials with good electric conductivity and large specific surface areas. On the other hand, Pt-based alloy catalysts, such as Pt-Au [10], Pt-Ni [11], Pt-Co [12], and $\mathrm{Pt}-\mathrm{Pd}$ [13], are introduced to obtain higher performance at lower Pt contents.

As to the fuel of DAFCs, many small molecule alcohols are of great superiority, due to their high energy density and ease of thorough decomposition. Among them, methanol is the most typical for a fuel cell containing one carbon (C1) atom [14]. In the early days of electro-catalytic research, methanol was the first small molecule compound to be used to study the catalytic oxidation DAFCs. Compared to other small molecules, the complete oxidation of methanol to produce a unit volume of $\mathrm{CO}_{2}$ produces the highest energy. Although methanol was most studied due to various advantages, the main problem of using methanol as a fuel for DAFCs is its high toxicity to the catalyst by the intermediate product in the oxidation process. Therefore, some alcohols that can replace methanol have been studied in depth. C2-alcohols, such as ethanol and ethylene glycol, are one of the more intensive alcohols studied. They not only have a higher energy density, but also have one break of the $\mathrm{C}-\mathrm{C}$ bond in the complete oxidation process. Since $\mathrm{C} 2$-alcohol also produces intermediates, such as $\mathrm{CO}$ or oxalic acid, during complete oxidation, the stability of electrocatalysts is a challenge. One of the motivations for studying glycerol with three carbons is that they can be used in direct alcohol fuel cells for electric energy generation, in addition to the symbiosis of heat and chemicals. In particular, glycerol is produced in large quantities as a by-product of biodiesel production and has a high energy content. Moreover, due to the unique structure of glycerol, a large number of chemicals with high economic value can be produced by chemical reactions. Electrochemical studies would be carried out using these representative alcohols as substrates. However, the complete oxidation of $\mathrm{C}-\mathrm{C}$ bonds to $\mathrm{CO}_{2}$ is a problem. $\mathrm{Pt}$ is now considered to be the best oxidation catalyst, but its ability to break $\mathrm{C}-\mathrm{C}$ bonds is limited [15].

Xu Changwei et al. $[16,17]$ systematically studied the electrochemical oxidation activity of Pd on various alcohols in alkaline media and found that $\mathrm{Pd} / \mathrm{C}$ had higher electrochemical oxidation activity for ethanol than $\mathrm{Pt} / \mathrm{C}$ in alkaline solution. At the same time, the catalytic activity and the anti-poisoning ability of ethanol oxidation on $\mathrm{Pd} / \mathrm{C}$ is much better than that of methanol oxidation. When oxides, like $\mathrm{CeO}_{2}, \mathrm{NiO}, \mathrm{Co}_{3} \mathrm{O}_{4}$, or $\mathrm{Mn}_{3} \mathrm{O}_{4}$, are combined with $\mathrm{Pd}$, the catalytic activity and stability can be significantly improved. It has been found that the $\mathrm{Pd}-\mathrm{NiO} / \mathrm{C}$ catalyst has unique properties for ethanol oxidation. The starting potential for oxidation is $200 \mathrm{mV}$ earlier than that of the $\mathrm{Pt} / \mathrm{C}$ catalyst. This result provides very valuable materials for the development of ethanol fuel cells. Claudio Bianchini and Pei Kang Shen [18] described and discussed many different types of anodes containing Pd-based electrocatalysts. They found that Pd nanocatalysts exhibit higher activity for the electrooxidation of monohydric alcohols and polyols in alkaline media. The remarkable feature of $\mathrm{Pd}$ catalysts for the electrooxidation of alcohols is that it is difficult to break the $\mathrm{C}-\mathrm{C}$ bonds, even in the strong alkaline media.

$\mathrm{Au}$ is inactive in acidic media for alcohol oxidation, while the surface becomes more active in alkaline media $[19,20]$. It has been reported [21] that no toxic intermediate products appeared and adsorbed on the surface of the Au electrode in alkaline solution. Au showed high electrocatalytic activity for electrochemical oxidation of ethanol, but excessive overpotential constrained its use. Some researchers [22] studied the gold-modified palladium as a catalyst for the electrochemical oxidation of isopropanol, and found that the catalytic activity of $\mathrm{Pd}$ was greatly improved. 
It is well known that conventional direct alcohol fuel cells use alkaline aqueous electrolyte. However, $\mathrm{CO}_{2}$ produced by complete oxidation of alcohols is converted into carbonate/bicarbonate in alkaline medium. Although it is now possible to solve this problem by using an anion exchange membrane, the use of the membrane increases the cost of the battery and brings about safety issues that cannot be ignored [23]. Therefore, it is necessary to study the use of acidic and neutral electrolytes.

Although previous researchers have conducted extensive research on anode reactions for DAFCs, there are relatively few lateral comparisons and correlations reported on the key factors, such as catalysts, fuels, and electrolytes, which is very important and has guiding significance for the study of DAFCs. However, most current research on precious metal catalysts is limited to one metal. Small molecule alcohols are used as an important substrate for fuel cells. The scope of its research is also relatively small. In addition, the comparison of electrolytes of different $\mathrm{pH}$ is also insufficient. Herein, in this paper, we attempted to investigate the electro-oxidation behaviors of some typical alcohols (methanol, ethanol, ethylene glycol, n-propanol, 2-propanol, and glycerol) over different electrodes in acidic, neutral, and alkaline media, respectively. The electrodes included are commercial $\mathrm{Pt}, \mathrm{Pd}$, and $\mathrm{Au}$ disk electrodes and self-synthesized Pt/CNTs, Pd/CNTs, and Au/CNTs coated electrodes. A cyclic voltammetry $(\mathrm{CV})$ method was used to test the catalytic performance of these electrodes to discover some regularities of those electro-oxidation reactions.

\section{Results and Discussion}

\subsection{Characterization of Pt/CNTs, Pd/CNTs, and Au/CNTs Catalysts}

The noble metal contents of the self-synthetized Pt/CNTs, Pd/CNTs, and Au/CNTs catalysts were firstly confirmed by ICP measurement and are listed in Table 1 . The Pt, Pd, and Au loading for these catalysts are well controlled at about 0.8 wt.\%. TEM and XRD patterns (shown in Figure 1) were introduced to observe the morphology and crystal structure of these catalysts. The relative results are also listed in Table 1. From the TEM images, nanoparticles were observed well dispersed on the surface of the CNT for all the catalysts. Their average diameters were similar at around 3.2 to $3.9 \mathrm{~nm}$. From the XRD patterns, the weak diffraction peaks of $\mathrm{Pt}, \mathrm{Pd}$, and Au were observed at $2 \theta$ of $38.2^{\circ}$, $39.1^{\circ}$, and $40^{\circ}$ for $\mathrm{Pt} / \mathrm{CNTs}, \mathrm{Pd} / \mathrm{CNTs}$, and $\mathrm{Au} / \mathrm{CNT}$, respectively. Based on the diffraction peaks, the grain sizes of the metal crystals were estimated to be 2.2, 2.3, and $2.4 \mathrm{~nm}$ for Pt/CNTs, Pd/CNTs, and $\mathrm{Au} / \mathrm{CNT}$, respectively, by the Scherrer formula.

Table 1. Structural parameters for Pt/CNTs, Pd/CNTs, and Au/CNTs catalysts measured by ICP, TEM, XRD, and Cu-UPD.

\begin{tabular}{cccccc}
\hline Catalysts & Metal Loading $^{\mathbf{a}} \mathbf{( \mathbf { w t } \% )}$ & Particle Size $^{\mathbf{b}} \mathbf{( \mathbf { n m } )}$ & Grain Size $^{\mathbf{c}} \mathbf{( \mathbf { n m } )}$ & $\left.\mathbf{2 \theta}^{\mathbf{d}} \mathbf{(}^{\circ}\right)$ & $\mathbf{E A S}^{\mathbf{e}}\left(\mathbf{m}^{\mathbf{2}} / \mathbf{g}\right)$ \\
\hline $\mathrm{Pt} / \mathrm{CNTs}$ & 0.85 & 3.2 & 2.2 & 38.2 & 110.0 \\
$\mathrm{Pd} / \mathrm{CNTs}$ & 0.75 & 3.6 & 2.3 & 39.1 & 123.0 \\
$\mathrm{Au} / \mathrm{CNTs}$ & 0.80 & 3.9 & 2.4 & 40 & 100.0 \\
\hline
\end{tabular}

${ }^{a}$ Metal loading amounts on the carbon support estimated from ICP analysis. ${ }^{b}$ Particle diameter of the catalysts from TEM images. ${ }^{c}$ Crystallite sizes of the catalysts calculated by line broadening of the powder XRD peak. ${ }^{\mathrm{d}}$ The XRD angular position of the corresponding metal. ${ }^{\text {e }}$ Electro-chemical surface areas measured by the Cu-UPD method.

The XPS spectra of Pt/CNTs, Pd/CNTs, and Au/CNTs catalysts are shown in Figure 2. We performed a deconvolution of the C 1 s spectra of CNTs into four peaks centered at $284.5 \pm 0.2$, $285.2 \pm 0.2,286.2 \pm 0.2$, and $288.9 \pm 0.2 \mathrm{eV}$. The peaks at 284.5 and $285.2 \mathrm{eV}$ can be assigned to $\mathrm{sp}^{2}$-hybryidized graphite-like carbon atoms and $\mathrm{sp}^{3}$-hybridized carbon atoms, respectively [24]. The peaks at 286.2 and $288.9 \mathrm{eV}$ are considered as $\mathrm{C}-\mathrm{O}-\mathrm{C}$ and $\mathrm{O}-\mathrm{C}=\mathrm{O}$ states, respectively [25]. Since CNTs have been oxidized by nitric acid, the $\mathrm{O} 1 \mathrm{~s}$ spectra of the three catalysts (Figure $2 \mathrm{c}, \mathrm{f}, \mathrm{i}$ ) can be deconvoluted into the peak at $533.6 \pm 0.1 \mathrm{eV}$ attributed to organic $\mathrm{C}=\mathrm{O}$ and the peak at $532.2 \pm 0.1 \mathrm{eV}$ attributed to organic $\mathrm{C}-\mathrm{O}$. In Figure $2 \mathrm{a}$, for $\mathrm{Pt} / \mathrm{CNTs}$, the larger two peaks at $74.8 \mathrm{eV}$ and $71.5 \mathrm{eV}$ represent metallic $\mathrm{Pt}$, and the smaller two peaks at $76 \mathrm{eV}$ and $72.78 \mathrm{eV}$ represent oxidized $\mathrm{Pt}$ in the 
divalent states. For the Pd 3d spectra of Pd/CNTs in Figure 2d, the doublet at $336.02 \mathrm{eV}$ and $341.28 \mathrm{eV}$ is due to Pd metal. Similarly, the doublet at $83.99 \mathrm{eV}$ and $87.71 \mathrm{eV}$ in Figure $2 \mathrm{~g}$ is assignable to Au metal.
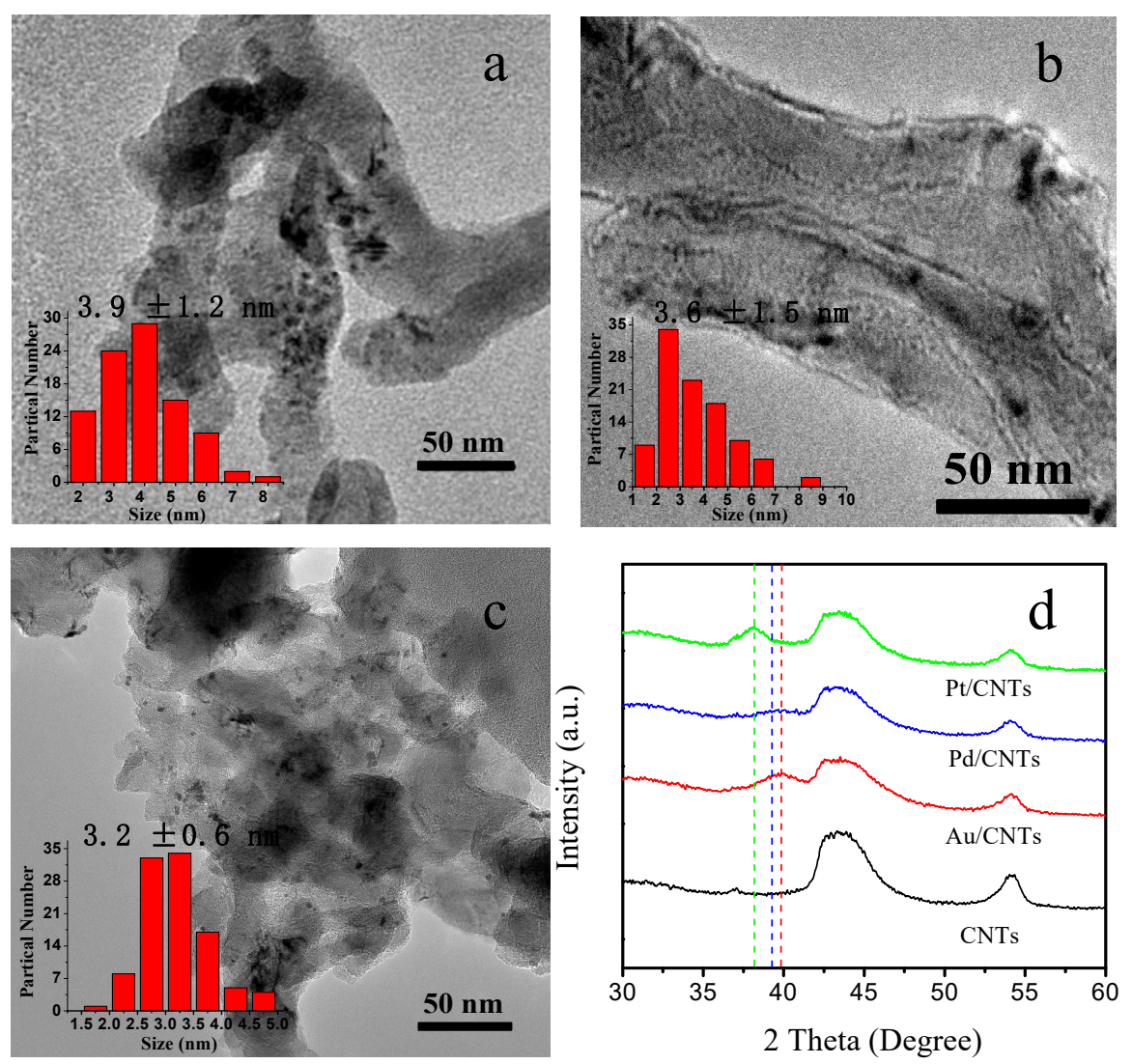

Figure 1. TEM images of $\mathrm{Au} / \mathrm{CNTs}(\mathbf{a}), \mathrm{Pd} / \mathrm{CNTs}(\mathbf{b}), \mathrm{Pt} / \mathrm{CNTs}(\mathbf{c})$, and XRD patterns (d) for them.

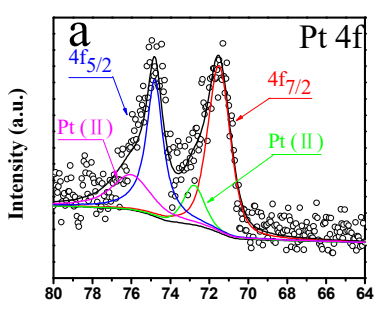

Binding Energy (eV)
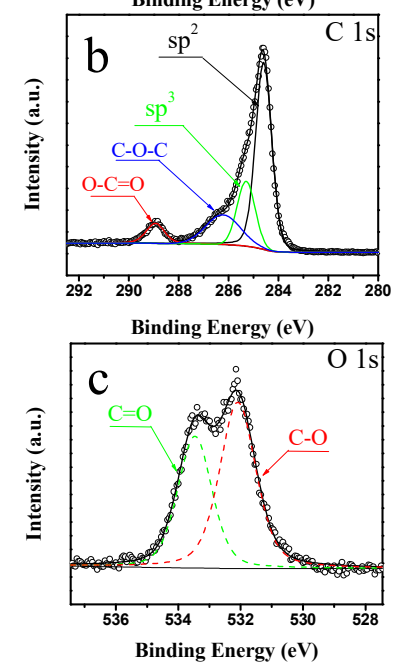
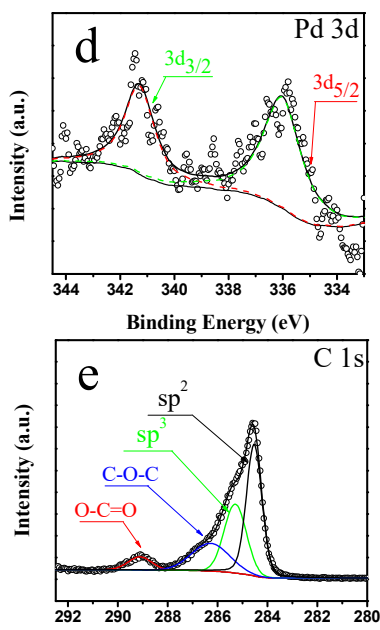

Binding Energy (eV)

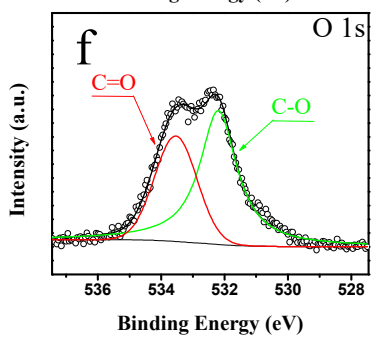

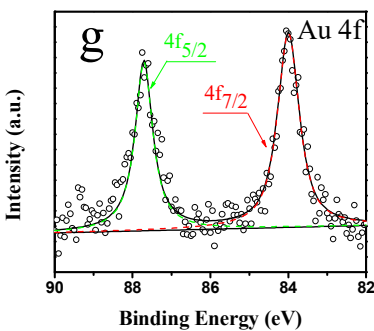
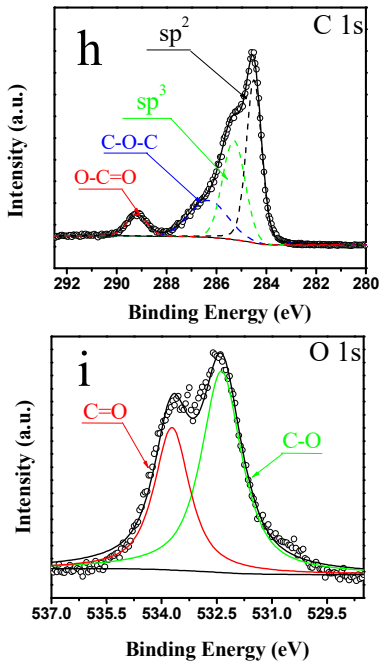

Figure 2. XPS spectra of Pt/CNTs (a-c), Pd/CNTs (d-f), and Au/CNTs (g-i) catalysts. 


\subsection{Electrochemical Characterization of $P t, P d$, and Au Disk Electrodes}

Cyclic voltammograms of commercial Pt, Pd, and Au disk electrodes in alkaline, acid, and neutral supporting electrolyte were conducted and are shown in Figure 3. The voltammogram of a Pt disk electrode recorded in $0.1 \mathrm{M} \mathrm{KOH}$ under $\mathrm{N}_{2}$ saturation displays three regions according to the applied potential (Figure 3a). Region I at lower potentials is associated with the adsorption (reduction peaks)-desorption (oxidation peaks) of hydrogen, whereas region III at higher potentials reveals the adsorption (oxidation peaks)-desorption (reduction peak) of oxygenated species at the electrode surface. Between them is the double-layer region II, where no net electrochemical reaction occurs, and which is characterized by small currents associated with the charge and discharge of the double-layer capacity [26]. The pattern of a Pd electrode is similar to that of a platinum electrode. However, the onset potential of region III is much more positive than that of a platinum electrode. In the case of the Au electrode, the hydrogen region disappeared.
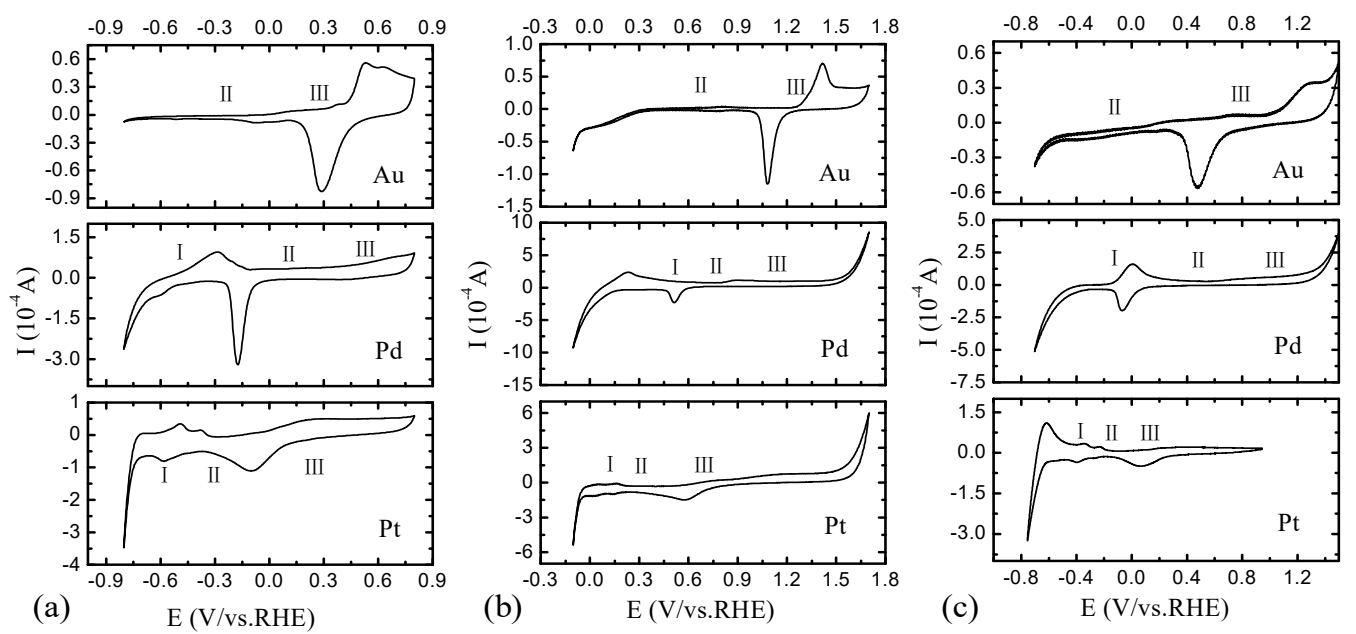

Figure 3. Cyclic voltammograms $\left(100 \mathrm{mV} \mathrm{s}^{-1}\right)$ of metal disk electrodes in different electrolytes with $\mathrm{N}_{2}$ saturated: $0.1 \mathrm{M} \mathrm{KOH} \mathrm{(a);} 0.1 \mathrm{M} \mathrm{HClO}_{4}(\mathbf{b})$; and $0.05 \mathrm{M} \mathrm{K}_{2} \mathrm{SO}_{4}$ (c).

When the same experiments were performed in acid medium, $0.1 \mathrm{M} \mathrm{HClO}_{4}$, and neutral medium, $0.05 \mathrm{M} \mathrm{K}_{2} \mathrm{SO}_{4}$, instead of alkaline electrolyte, the main features of both voltammograms remain unchanged (Figure $3 \mathrm{~b}$ for acid and Figure $3 \mathrm{c}$ for neutral supporting electrolyte). For a Pt disk electrode, the onset potential of the oxygen region, which is related to earlier $\mathrm{OH}$ adsorption, gradually becomes positive as the electrolyte's $\mathrm{pH}$ decreases. When the $\mathrm{pH}$ varies from 1 to 13 , the range of the onset potential is about -0.2 to $0.4 \mathrm{~V} / \mathrm{vs}$. RHE. However, when it comes to Pd electrodes, except that the onset potential of the oxygen region is $0.1 \mathrm{~V}$ when the $\mathrm{pH}$ is 13 , the onset potential in neutral medium is $0.6 \mathrm{~V}$. When the $\mathrm{pH}$ is 1 , the potential is as high as $0.75 \mathrm{~V}$. The onset potential for an Au electrode in acidic and neutral media is more positive than $\mathrm{Pd}$. When the $\mathrm{pH}$ is 13 , the onset potential for $\mathrm{Pd}$ is $0.15 \mathrm{~V}$ and for $\mathrm{Au}$ it is about $0.35 \mathrm{~V}$. Although the onset potential changes when other solutes are present in the solution, these phenomena may explain part of the results, which will be given below.

The electrochemical active surface area (EAS) of Pt/CNTs, Pd/CNTs, and $\mathrm{Au} / \mathrm{CNTs}$ were measured by a $\mathrm{Cu}-\mathrm{UPD}$ method and calculated by the following equation:

$$
\operatorname{EAS}\left(m^{2} / g\right)=\frac{Q_{C u}}{0.042 \cdot w(g)}
$$

where $Q_{C u}$ was the average electric quantity of copper stripping and $w$ represents the content of noble metal on the working electrode. Where $Q_{\mathrm{C} u}$ is calculated by the following formula:

$$
Q_{C u}(C)=\frac{s}{f}
$$


where $s$ is the area of the oxidation peak of the alcohol after subtracting the background and $f$ represents the scan rate of the cyclic voltammetry.

The CV results are shown in Figure 4. As listed in Table 1, EAS for Pt/CNTs, Pd/CNTs, and $\mathrm{Au} / \mathrm{CNTs}$ are $110.0,123.0$, and $100.0 \mathrm{~m}^{2} / \mathrm{g}$, respectively.
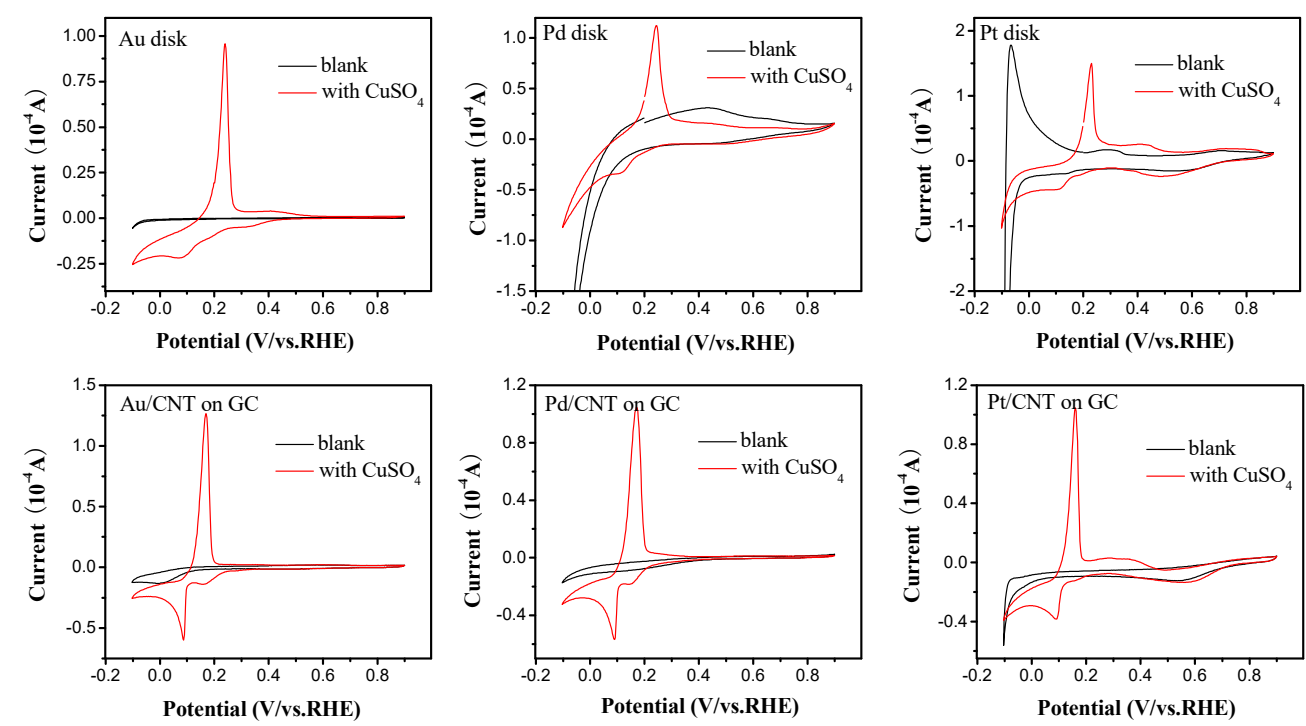

Figure 4. Cyclic voltammograms $\left(100 \mathrm{mV} \mathrm{s}^{-1}\right)$ of $\mathrm{Cu}-\mathrm{UPD}$ in $0.5 \mathrm{M} \mathrm{H}_{2} \mathrm{SO}_{4}$ in the absence and presence of $1 \mathrm{mMCuSO}_{4}$.

\subsection{Electrocatalytic Oxidation Behaviors of Alcohols over Different Electrodes}

The electro-oxidation behaviors of different alcohols over different electrodes were researched by CV curves. Figures 5-7 shows the forward peaks of CV curves for the oxidation of methanol, ethanol, ethylene glycol, n-propanol, 2-propanol, and glycerol over Pt, Pd, and Au electrodes in alkaline, acidic, and neutral media, respectively. The acid-base property of the electrolyte media was shown as a dominating influencing factor for the catalytic activity of all these electrodes. As shown in Figure 5, in alkaline media, alcohol oxidation peaks appeared in the corresponding potential range over all electrodes. However, in acidic and natural media, oxidation peaks emerged on only Pt electrodes (as shown in Figures $6 \mathrm{C}$ and $7 \mathrm{C}$ ), but hardly any oxidation signals were observed on Pd and $\mathrm{Au}$ electrodes (as shown in Figure 6A,B and Figure 7A,B). It indicated that Pt, Pd, and Au have catalytic activities in alkaline media, while only Pt have catalytic activities in acidic and natural media. After comparing CV peaks for Pt electrodes in the three kinds of media (as shown in Figures 5C, 6C and 7C), we found that the lowest onset potential and highest current density were mostly emerged in alkaline media, and the situation was contrary in neutral media. It demonstrated that alkaline media is best for the electro-oxidation of these alcohols, and then acidic media is better than neutral media.

The onset potential and current density of the CV peaks can be used to quantitatively analyze the catalytic performance of electro-oxidation reactions. Especially, the onset potential of the oxidation peak usually stands for the energy barrier of the reaction. Peak current density represents the maximum reaction rate. At this point, the diffusion rate and the reaction rate are balanced [27]. The method used to find the onset potential in this paper is to find the point at which the derivative of the current density with respect to the potential is zero. In addition, the peak potential can also be found by this method. The corresponding one is also the point where the derivative is zero [28]. The current density corresponding to the peak potential is the peak current density. The potential corresponding to this point is the onset potential. As shown in Figure 8 we present an example. In the end, the initial potential of the electro-oxidation of ethanol on the Pt electrode is $-0.3995 \mathrm{~V}$ (vs. RHE). For the convenience of correlation analysis, the onset potential and current density data of CV peaks are generalized in Figures 9 and 10, respectively. Obviously, the lowest onset potential and highest 
current density mostly emerged over both the Pt disk and Pt/CNT electrodes, except for the oxidation of ethanol and n-propanol. From the overall perspective of Figure 10, Pt's activity is the best for the oxidation of most alcohols, while Pd is in the medium. However, in alkaline media, this regularity is not completely accorded with in the oxidation of ethanol, n-propanol, and glycerol. Additionally, polylols (ethylene glycol and glycerol) are oxidized more easily and have a resulting higher current density than other alcohols, especially on Au electrodes.
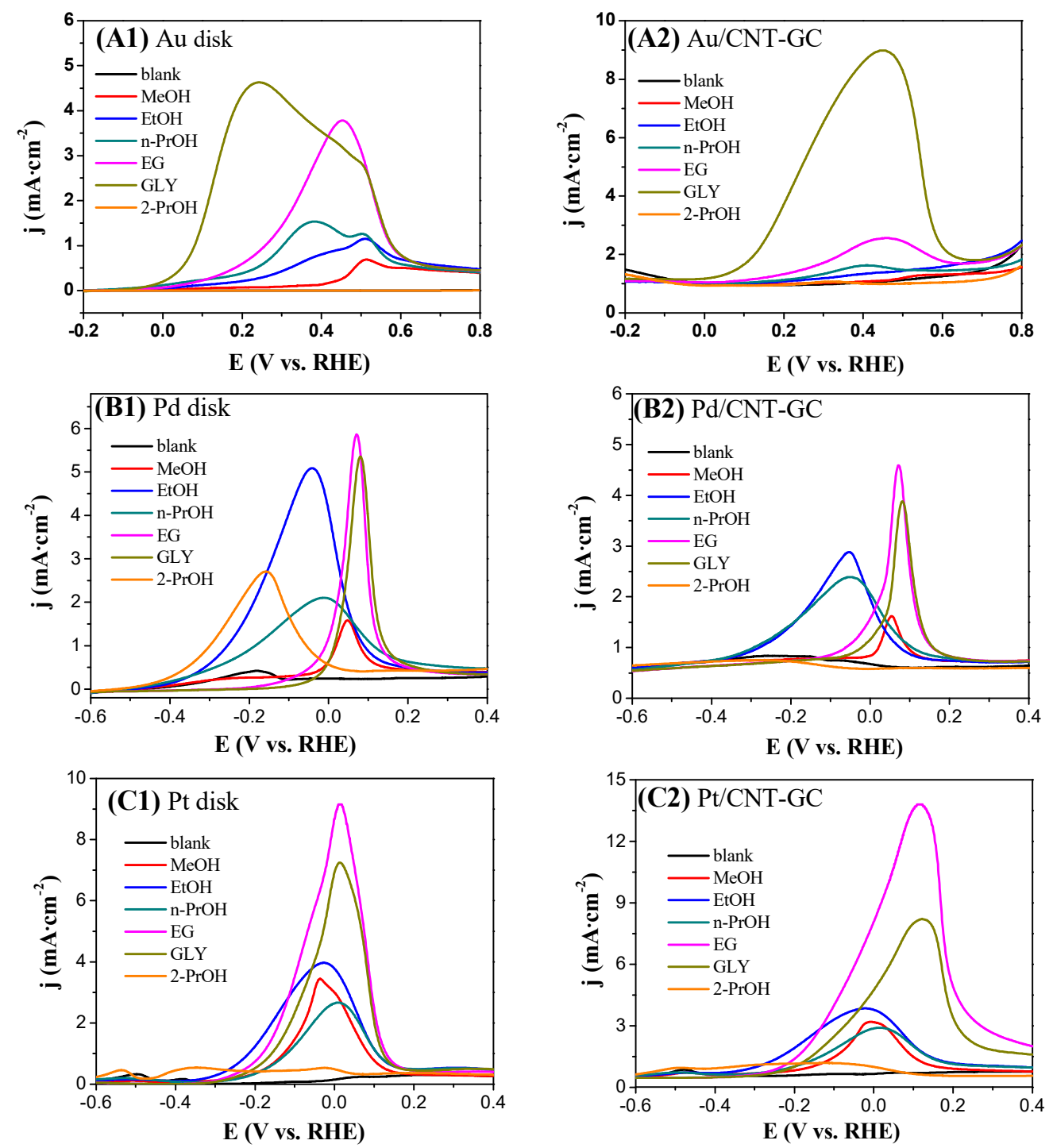

Figure 5. Voltammetry curves $\left(100 \mathrm{mV} \mathrm{s}^{-1}\right)$ of alcohol electro-oxidation over different electrodes in $0.1 \mathrm{M} \mathrm{KOH}$ solution.

Combining the trend lines of Figure 9A,B, we found that for the electrocatalytic alcohol reaction by the same catalyst, the rate of electrooxidation in an alkaline medium is much greater than that in acidic and neutral media. Additionally, in acidic and neutral media, we could not find a clear rule. Alcohols are more incompletely oxidized in acidic and neutral media. 

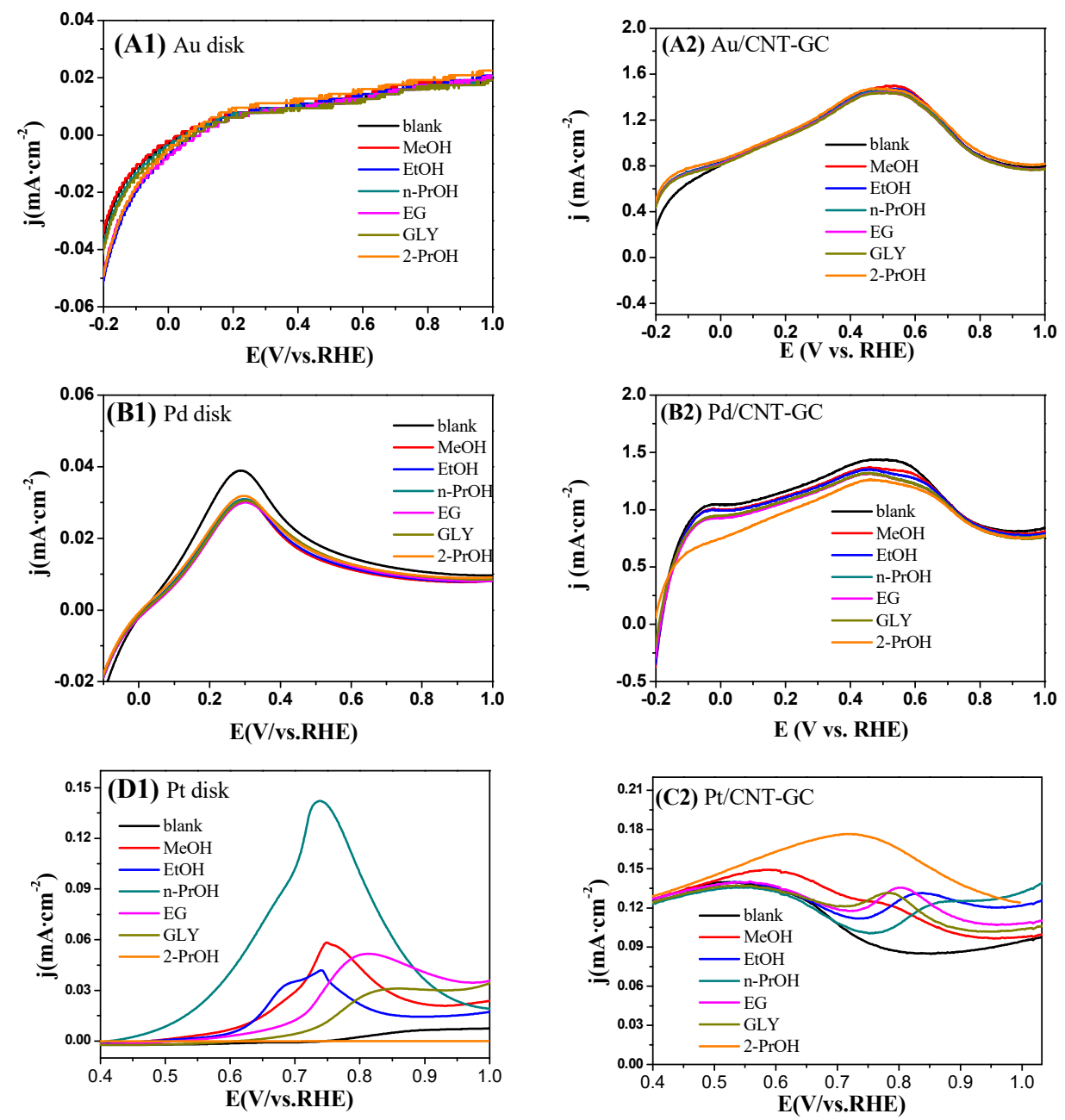

Figure 6. Voltammetry curves of alcohol electro-oxidation over different electrodes in $0.1 \mathrm{M}$ $\mathrm{HClO}_{4}$ solution.

After comparing the onset potentials for the oxidation of normal monohydric alcohols (methanol, ethanol, and n-propanol) in Figure 10A, the alcohol with a longer carbon chain has more negative potential over the Pt electrodes. However, this regularity is the opposite over Pd and Au electrodes. It means that normal monohydric alcohols with longer carbon chains to start to be oxidized on Pt electrodes more easily, while those with shorter carbon chains start to be oxidized on Pd and $\mathrm{Au}$ electrodes more easily. When comparing the onset potentials for the oxidation of n-propanol, 2-propanol, ethylene glycol, and glycerol in Figure 9A, we found that those alcohols (2-propanol, glycerol) with a secondary hydroxyl group are oxidized more easily on Au electrodes than similar alcohols (n-propanol and ethylene glycol) without a secondary hydroxyl group. This regularity is also the opposite over Pt electrodes. It is suspected that $\mathrm{Pt}$ is more favorable towards the attack of the primary hydroxyl group, while Au is more favorable to the attack of the secondary hydroxyl group in our reaction conditions. This conclusion is the same as that of Mario Simoes et al. [20] for the electrooxidation of glycerol. From the overall perspective of Figure 10B, alkaline medium is most beneficial for the oxidation of most alcohols, while acid medium is in the medium. Moreover, the onset potential in acidic media is similar to that in neutral media. 

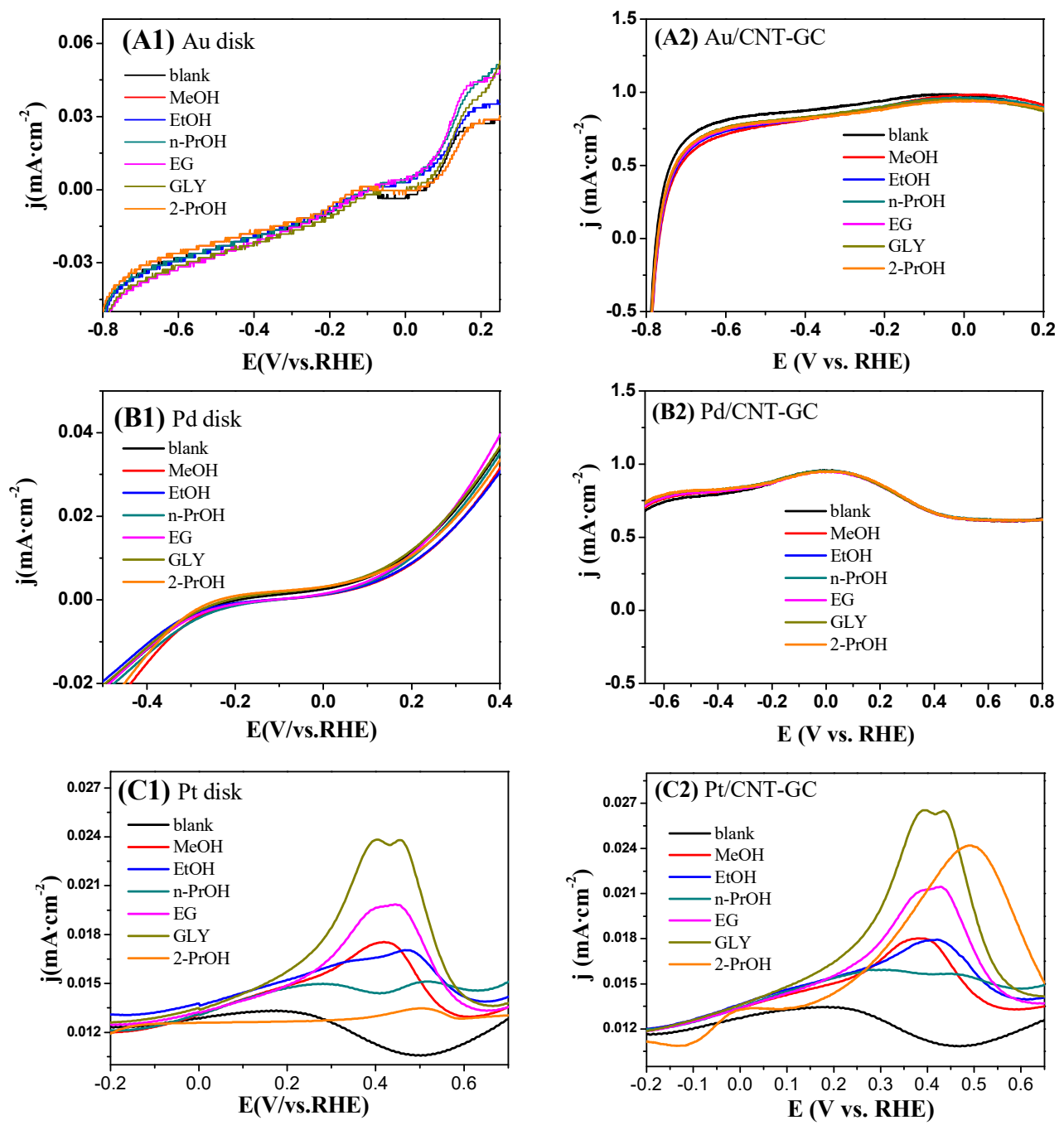

Figure 7. Voltammetry curves of alcohol electro-oxidation over different electrodes in $0.05 \mathrm{M}$ $\mathrm{K}_{2} \mathrm{SO}_{4}$ solution.

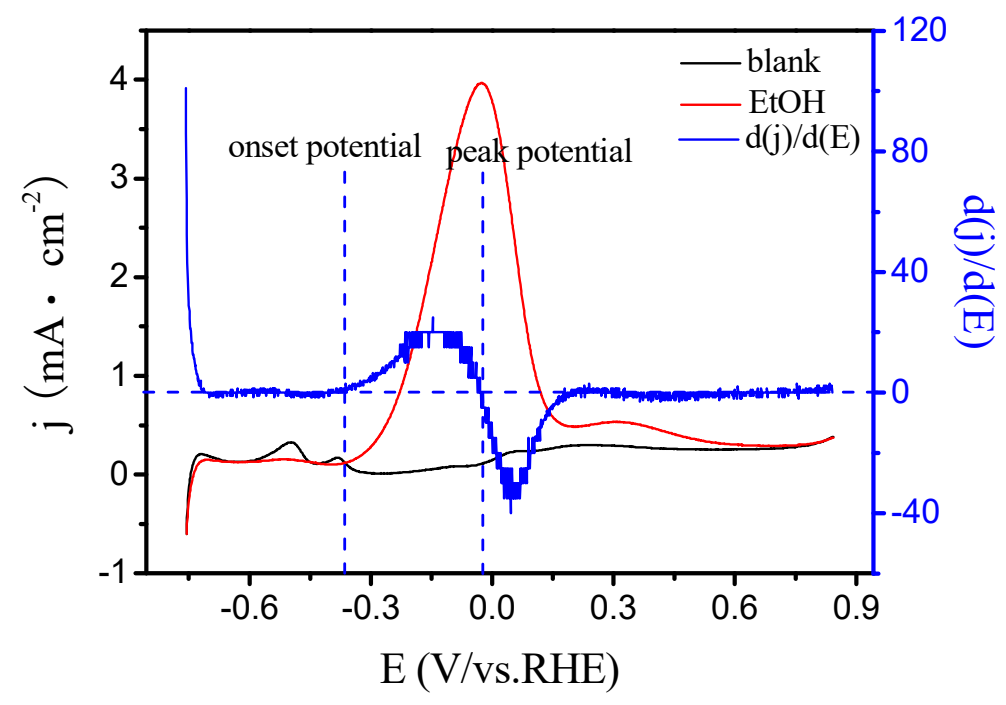

Figure 8. Linear sweep voltammetry of ethanol oxidation on a Pt electrode in $0.1 \mathrm{M} \mathrm{KOH}$ solution. Blue line: The current density of ethanol oxidation takes a derivative with respect to the potential. 

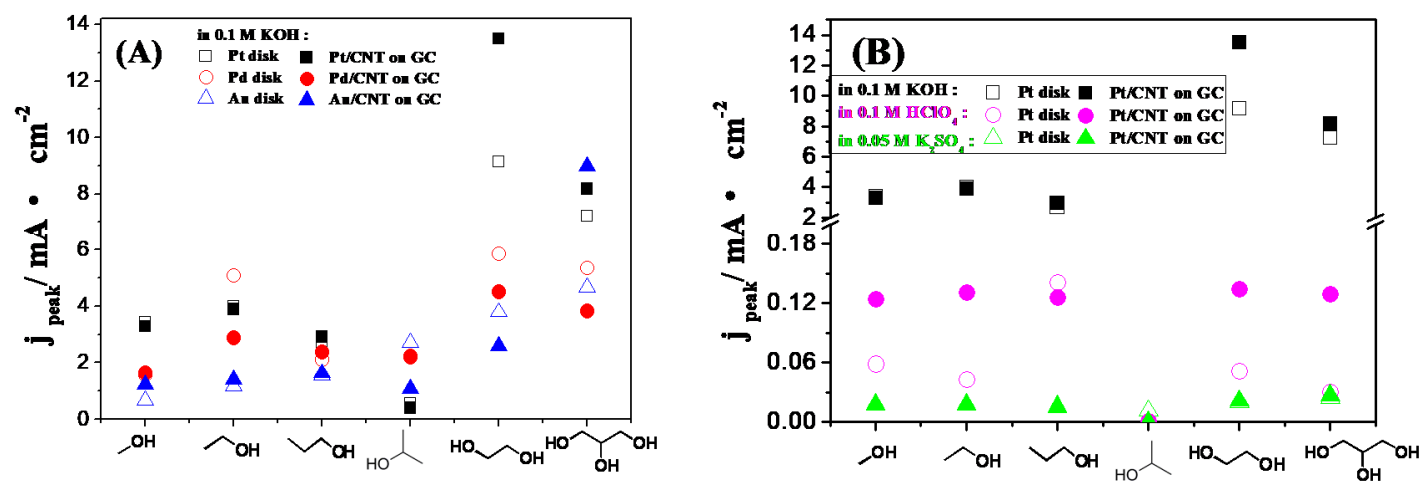

Figure 9. Comparison of the current density of electro-oxidation over different electrodes in $0.1 \mathrm{M}$ $\mathrm{KOH}$ solution (A) and over a Pt electrode in different solutions (B). Hollow icons are for metal disk electrodes; solid icons are for nanocatalyst covered GC disk electrodes.
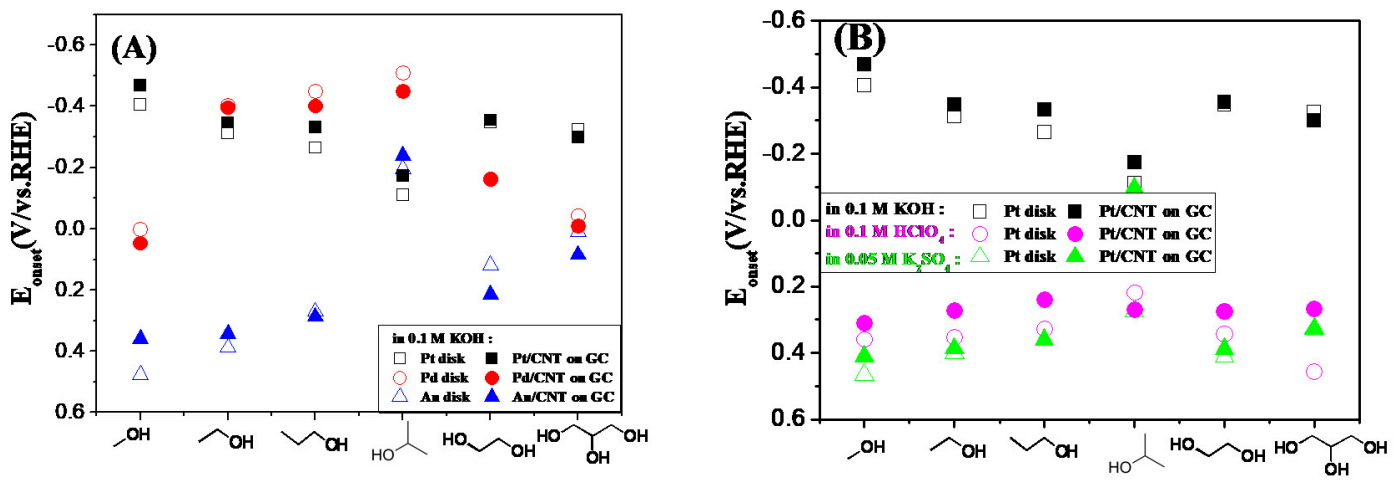

Figure 10. Comparison of the onset potential of electro-oxidation over different electrodes in $0.1 \mathrm{M}$ $\mathrm{KOH}$ solution (A) and over a Pt electrode in different solutions (B). Hollow icons are for metal disk electrodes; solid icons are for nanocatalyst covered GC disk electrodes.

The hydrogen bond donation ability (HBD) is a major property parameter of organic solvents; the larger the HBD, the stronger the proton donation ability [29]. This property of different alcohols may have a great influence on their oxidization reactions. Thus, we attempted to use HBD to analyze the electro-oxidation behaviors of different alcohols. The oxidation of glycerol is relatively specific and is related to the intrinsic properties of the catalyst [30]. Therefore, the oxidation of glycerol is not discussed here. The correlations between the onset potential and HBD of alcohols over different electrodes in alkaline media are shown in Figure 11A. The catalytic ability of different electrodes for alcohols' oxidation was found to have a certain correlation with the HBD of various alcohols. On Pt electrodes, as the HBD increases, the onset potential decreases. The relationship is contrary on Au and Pd electrodes. The relationship over the Pt electrode in alkaline media is contrary to that in acidic and natural media. The main reason for the relationships might be that the oxidation of alcohols has two important elementary steps: Firstly, the adsorption of alcohols by dehydrogenation of the -OH group, and followed by the electrolysis of protons combined with the hydroxide ions provided by the adsorbed water [31]. The second step contributes the current at the onset of the electron oxidation reaction. The rate-limiting step of alcohols' electro-oxidation on Pt catalysts is the removal of protons [14]:

$$
\begin{gathered}
\mathrm{CH}_{3} \mathrm{OH}+\mathrm{Pt} \rightarrow \mathrm{Pt}-\mathrm{CH}_{3} \mathrm{OH}_{\mathrm{ads}} \\
\mathrm{Pt}-\mathrm{CH}_{3} \mathrm{OH}_{\mathrm{ads}} \rightarrow \mathrm{Pt}-\mathrm{CO}_{\mathrm{ads}}+4 \mathrm{H}^{+}+4 \mathrm{e}^{-}
\end{gathered}
$$



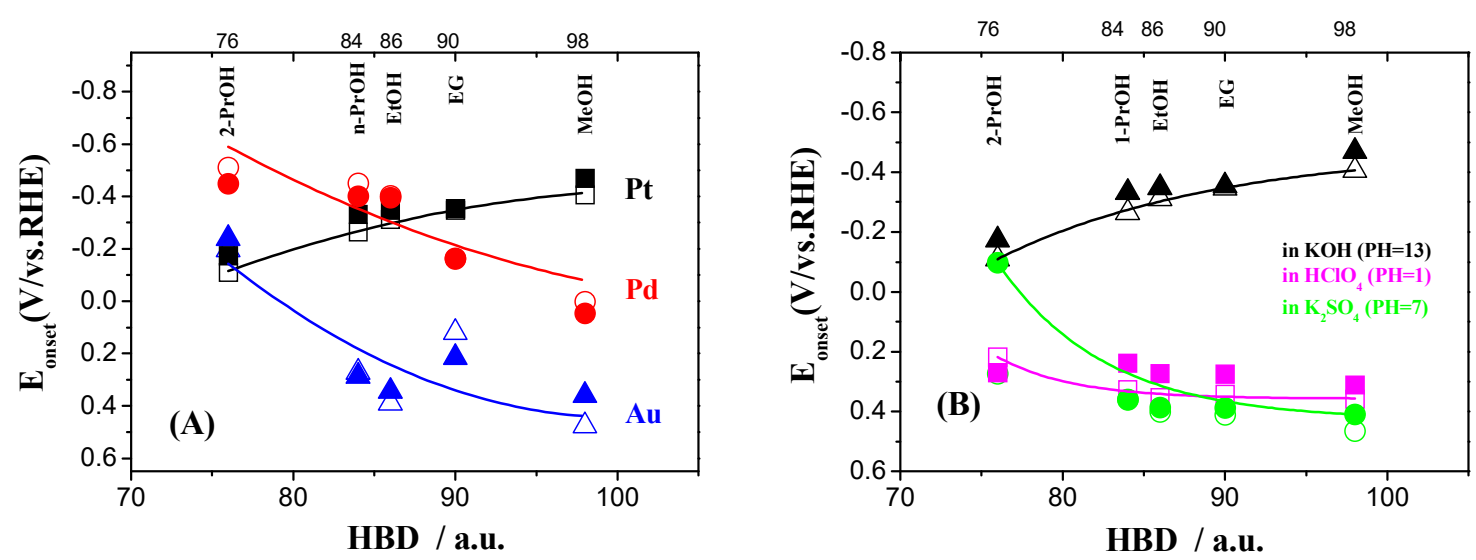

Figure 11. Correlations between electro-oxidation performance and hydrogen bond donation ability (HBD) of alcohols over different electrodes in $0.1 \mathrm{M} \mathrm{KOH}$ solution (A) and over a Pt electrode in different solutions (B). Hollow icons are for metal disk electrodes; solid icons are for nanocatalyst covered GC disk electrodes.

So, as the HBD increases, the activity of alcohols' electrooxidation increases. At low over potentials on Pd catalysts, hydroxyl adsorption is the rate-determining step [32]:

$$
\mathrm{Pd}+\mathrm{OH}-\rightarrow \mathrm{Pd}-\mathrm{OH}_{\mathrm{ads}}+4 \mathrm{e}^{-}
$$

From the results of $\mathrm{Na} \mathrm{Li}$ et al. [33], the activity of the electrooxidation of alcohols as a surface reaction is determined by the coverage of $\mathrm{OH}^{-}$on the $\mathrm{Au}$ surface. In short, the adsorption and dissociation of water on $\mathrm{Pd}$ and $\mathrm{Au}$ catalysts at low potentials becomes a rate-determining step. The larger the HBD of the alcohol, the harder the electrolysis of water, which results in the lower catalytic activity. The correlations between the onset potential and HBD of alcohols over the Pt electrode in different medias are shown in Figure 11B. The adsorption and dissociation of water on $\mathrm{Pd}$ and $\mathrm{Au}$ catalysts becomes quite difficult in acidic and neutral media. It means that Pd and Au catalysts have no significant activity on alcohol oxidation in acidic and neutral media. The case of Pt catalysts in acidic and neutral media is similar to that of $\mathrm{Pd}$ and $\mathrm{Au}$ in alkaline medium. The adsorption and dissociation of water becomes a rate-determining step. The larger the HBD of the alcohol, the lower the catalytic activity.

The electrooxidation of alcohols is a surface reaction, its adsorption process is very important. Thus, the above rules are also explained from the viewpoint of adsorption energy. Table 2 lists the adsorption energies of water, methanol, and ethanol on Pt, Pd, and Au surfaces calculated by DFT all within the generalized gradient approximation proposed by Perdew-Burke-Ernzerhof [34-40]. As shown in Table 2, the adsorption energies of water on Pt and Pd are similar, while the adsorption energies of methanol and ethanol on Pd are almost twice as high as those on Pt. It indicated that both water and alcohols can be absorbed on Pt sites, thus the proton from alcohol dehydrogenation can be transferred to water and generate current. Thus, over the Pt electrode, when the alcohol is more easily dehydrogenated (with higher HBD value), the reaction carries on more easily. That might be why we observed the onset potential decreases as the HBD increased over the Pt electrode, as shown in Figure 11. It is reasonable that a positive correlation was found between the catalytic activity and HBD over the Pt electrode with moderate adsorption energies for both the subtracted and solvent molecule. T. Iwasita et al. [41] synthesized PtRu alloy and used in situ FTIR to study the energy change of the surface on the adsorption of matter during methanol oxidation, and proved that the addition of $\mathrm{Ru}$ makes the adsorption of $\mathrm{Pt}$ to methanol weaker, which is more conducive to the oxidation of methanol. However, over the Pd catalyst, as the adsorption energies for alcohols are much higher than that of water, alcohol molecules easily occupy most of the active sites, and block the proton transmission channel. Based on the results of Tian Sheng et al. [39], the adsorption energy of 
methanol $(-0.51 \mathrm{eV})$ and ethanol $(-0.74 \mathrm{eV})$ on the catalytic center of $\mathrm{Pd}_{-}-\mathrm{OH}_{\mathrm{ads}}$ is much larger than that of $\mathrm{H}_{2} \mathrm{O}$ on the surface active site of $\mathrm{Pd}(-0.33 \mathrm{eV})$. This causes the adsorption of a single layer of alcohol molecules on the surface of $\mathrm{Pd}$, and even the formation of a structure of a two-layer alcohol molecule [36]. In this case, the higher HBD of alcohol means it is more easily adsorbed to the Pd surface. The active site of the adsorbed $\mathrm{H}_{2} \mathrm{O}$ is reduced, and it becomes more difficult for the reaction to carry on. It is in accordance with the negative correlation between the catalytic activity and HBD over the Pd electrode. The adsorption of alcohols and water over the Au surface is similar to that of the $\mathrm{Pd}$ surface, and Au adsorbs alcohol more strongly than water. Thus, a negative correlation between the catalytic activity and HBD was also detected over the Au electrode. Rakesh K. Pandey and V. Lakshminarayanan analyzed Tafel plots and found that the plots of the gold loaded on conductive polymer material systems fitted two slopes at lower and higher potentials [42]. The higher slope at higher potentials indicates that the adsorption of intermediate carbonaceous species became stronger, and these substances occupied the active site of $\mathrm{Au}$, resulting in an inability to form new $\mathrm{Au}-\mathrm{OH}_{\mathrm{ads}}$. Therefore, HBD is inversely related to the ease of the reaction. Chuancheng Jia et al. proved that the highly active photo-generated intermediates on the surface of $\mathrm{TiO}_{2}$ can freshen the inert $\mathrm{Au}$ surface oxides, thereby increasing the catalytic activity of the catalyst [43].

Table 2. Adsorption energies (Eads) for $\mathrm{H}_{2} \mathrm{O}$, methanol, and ethanol on several metal surfaces.

\begin{tabular}{cccc}
\hline Metal & $\mathbf{H}_{2} \mathbf{O}_{\text {ads }}-\mathbf{E}_{\text {ads }}(\mathbf{e V})[34]$ & $\mathbf{C H}_{3} \mathbf{O H}_{\text {ads }}-\mathbf{E}_{\text {ads }}(\mathbf{e V})$ & $\mathrm{C}_{2} \mathbf{H}_{5} \mathbf{O H}_{\text {ads }}-\mathbf{E}_{\text {ads }}(\mathbf{e V})$ \\
\hline $\mathrm{Pt}$ & -0.35 & $-0.32[35]$ & $-0.37[38]$ \\
$\mathrm{Pd}$ & -0.33 & $-0.51[36]$ & $-0.74[39]$ \\
$\mathrm{Au}$ & -0.13 & $-1.18[37]$ & $-0.56[40]$ \\
\hline
\end{tabular}

The apparent activation energies $\left(E_{a}\right)$ for alcohol oxidation were measured and used to characterize the activity of the catalyst on electo-oxidizing alcohols [44]. Figures 12-14 show the linear sweep voltammetry (LSV) at different temperatures and their Arrhenius plots of alcohol eletro-oxidation on electrodes at peak potentials. According to the slope of the Arrhenius plots, $E_{a}$ values were obtained as follows [45]:

$$
E_{a}=-\mathrm{R}\left(\frac{\partial \operatorname{lnj}}{\partial(1 / \mathrm{T})}\right)_{E}
$$

The $E_{a}$ values for alcohol electrooxidation at peak potentials are shown in in Figures 12d, 13d and 14d. Over the Au electrode in alkaline media (Figure 12d), compared with blank linear voltammetry, it was found that $\mathrm{Au}$ had almost no electrooxidation activity for methanol. The activation energy of glycerol oxidation is $27.5 \mathrm{KJ} / \mathrm{mol}$, and is obviously lower than the oxidation of n-propanol $(42.2 \mathrm{KJ} / \mathrm{mol})$. It indicated that $\mathrm{Au}$ is more favorable of attacking the secondary and polybasic hydroxyl group in our reaction conditions, and it is in accordance with the results of Simoes et al.'s work on the electrochemical valorisation of glycerol [20]. Under similar conditions, the lowest activation energy was measured in the oxidation of n-propanol over the Pd electrode. The $E_{a}$ values of glycerol oxidation $(44.9 \mathrm{KJ} / \mathrm{mol})$ and methanol oxidation $(67.7 \mathrm{KJ} / \mathrm{mol})$ are much higher than that of n-propanol $(14.4 \mathrm{KJ} / \mathrm{mol})$ over the $\mathrm{Pd}$ electrode. Based on previous research, the characteristics of $\mathrm{Pd}$ of having strong $\mathrm{C}-\mathrm{C}$ bonds [18] and strong adsorption of its active site to the ethoxy group $\left(\left(\mathrm{CH}_{3} \mathrm{CO}\right)_{\mathrm{ads}}\right)$ [46] jointly determine this rule. For the Pt electrode, the activation energy of methanol oxidation $(44.1 \mathrm{KJ} / \mathrm{mol})$ is the smallest, and is much lower than the oxidation of n-propanol $(50.7 \mathrm{KJ} / \mathrm{mol})$ and glycerol $(61.7 \mathrm{KJ} / \mathrm{mol})$. This is due to the mechanism of the oxidation of alcohols on the Pt electrode. In the alkaline medium, the rate-limiting step of alcohol oxidation is the removal of protons from the alcohol adsorbed on the $\mathrm{Pt}$ electrode. Methanol has the largest HBD and the strongest proton capacity, so the activation energy is the lowest. The kinetic data was found to be in agreement with the data of the current density and onset potential of alcohol electro-oxidation. They were all released at a similar regularity of the catalytic activity, and affected by the alcohol's molecular structure. Pt electrodes showed the best activities 
on the oxidation of $\mathrm{C} 1$ alcohol, Pd electrodes were more active on the oxidation of C2-3 monobasic alcohols, and Au electrodes were more active on the oxidation of polybasic and secondary alcohols.
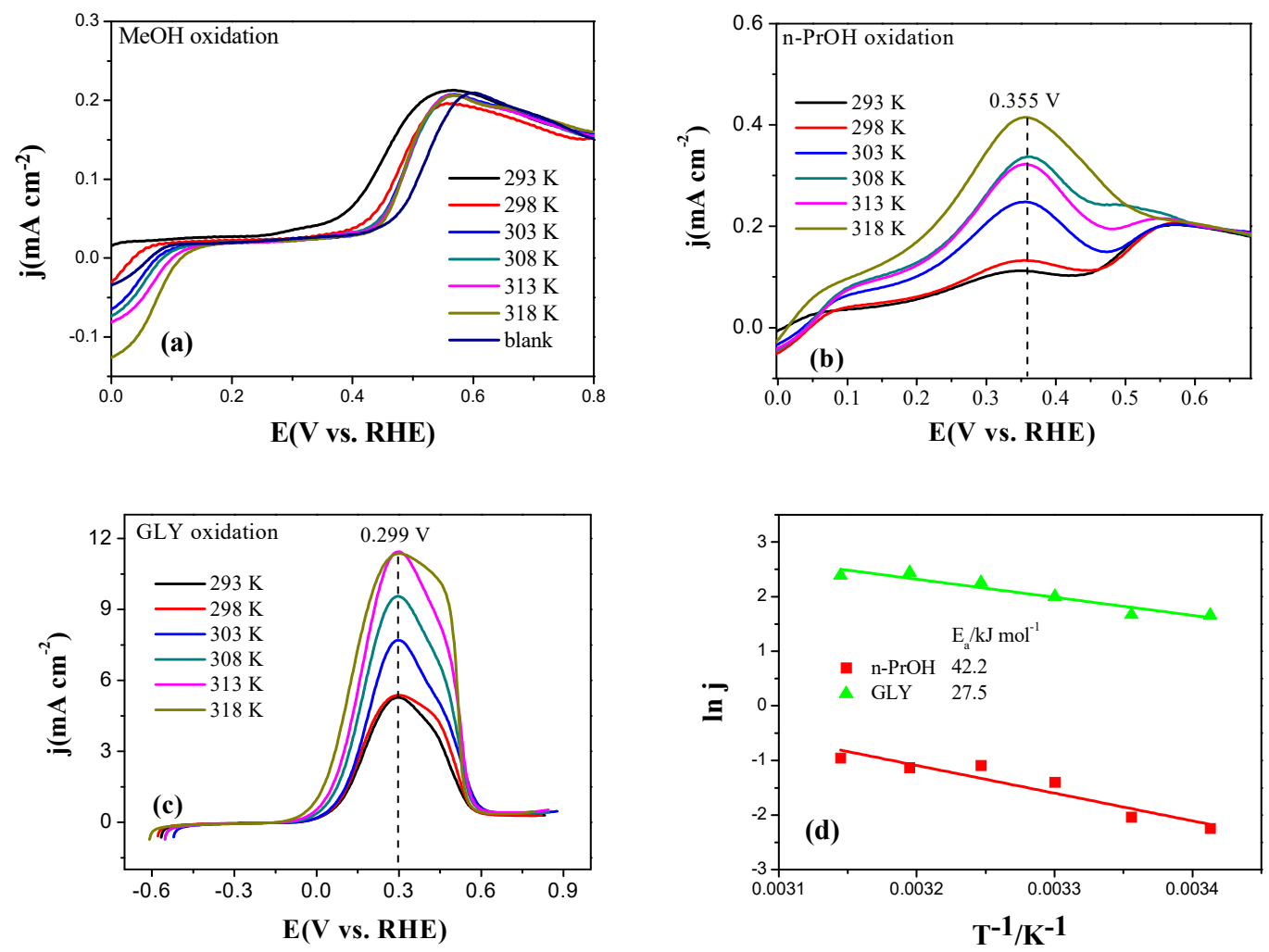

Figure 12. (a-c) Linear scan curves (LSVs) of Au electrode in $0.1 \mathrm{M} \mathrm{KOH}+0.025 \mathrm{M}$ alcohol; (d) Arrhenius plot of alcohol eletro-oxidation on $\mathrm{Au}$ at peak potentials.
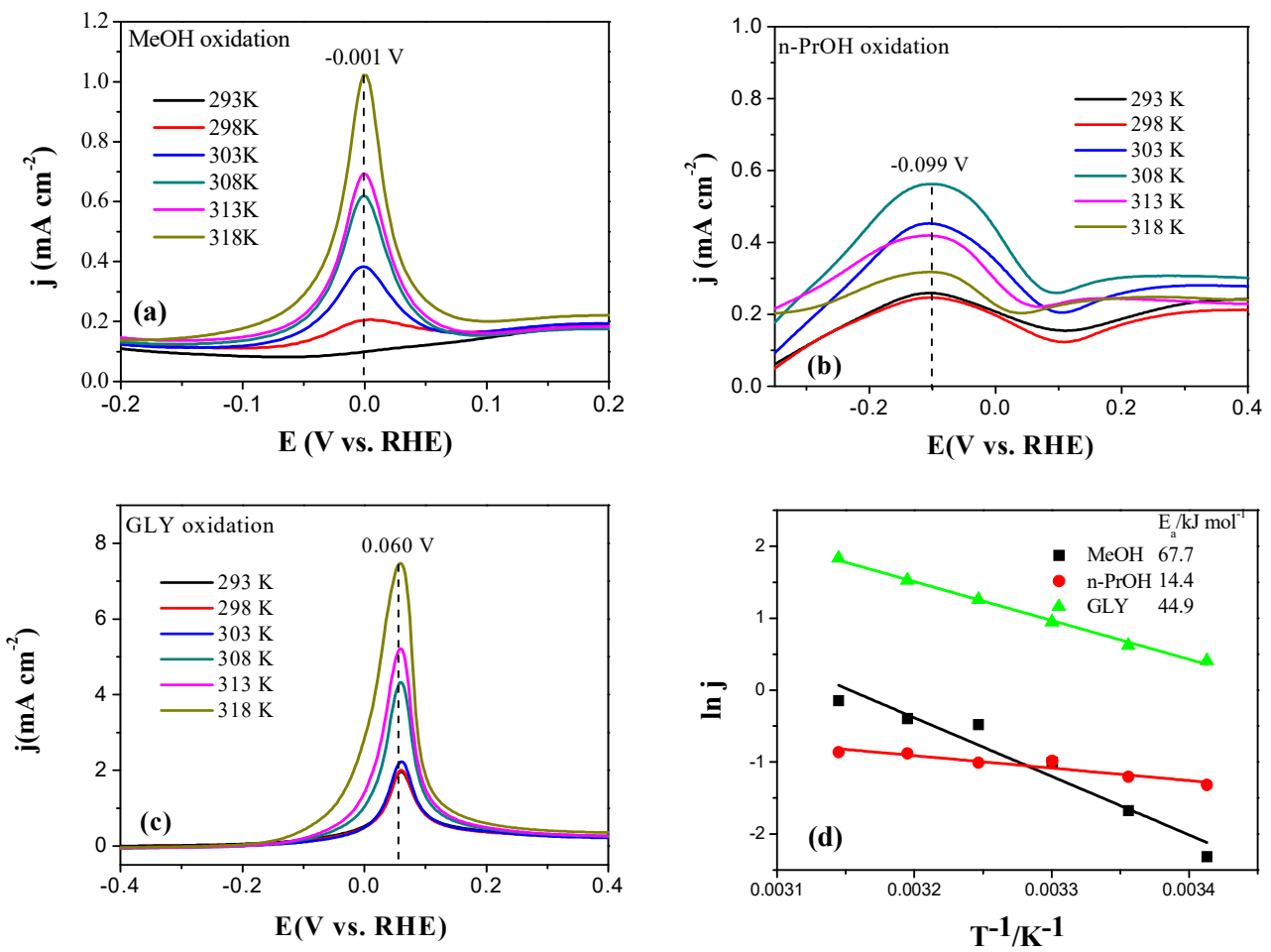

Figure 13. (a-c) LSVs of Pd electrode in $0.1 \mathrm{M} \mathrm{KOH}+0.025 \mathrm{M}$ alcohol; (d) Arrhenius plot of alcohol eletro-oxidation on $\mathrm{Pd}$ at peak potentials. 

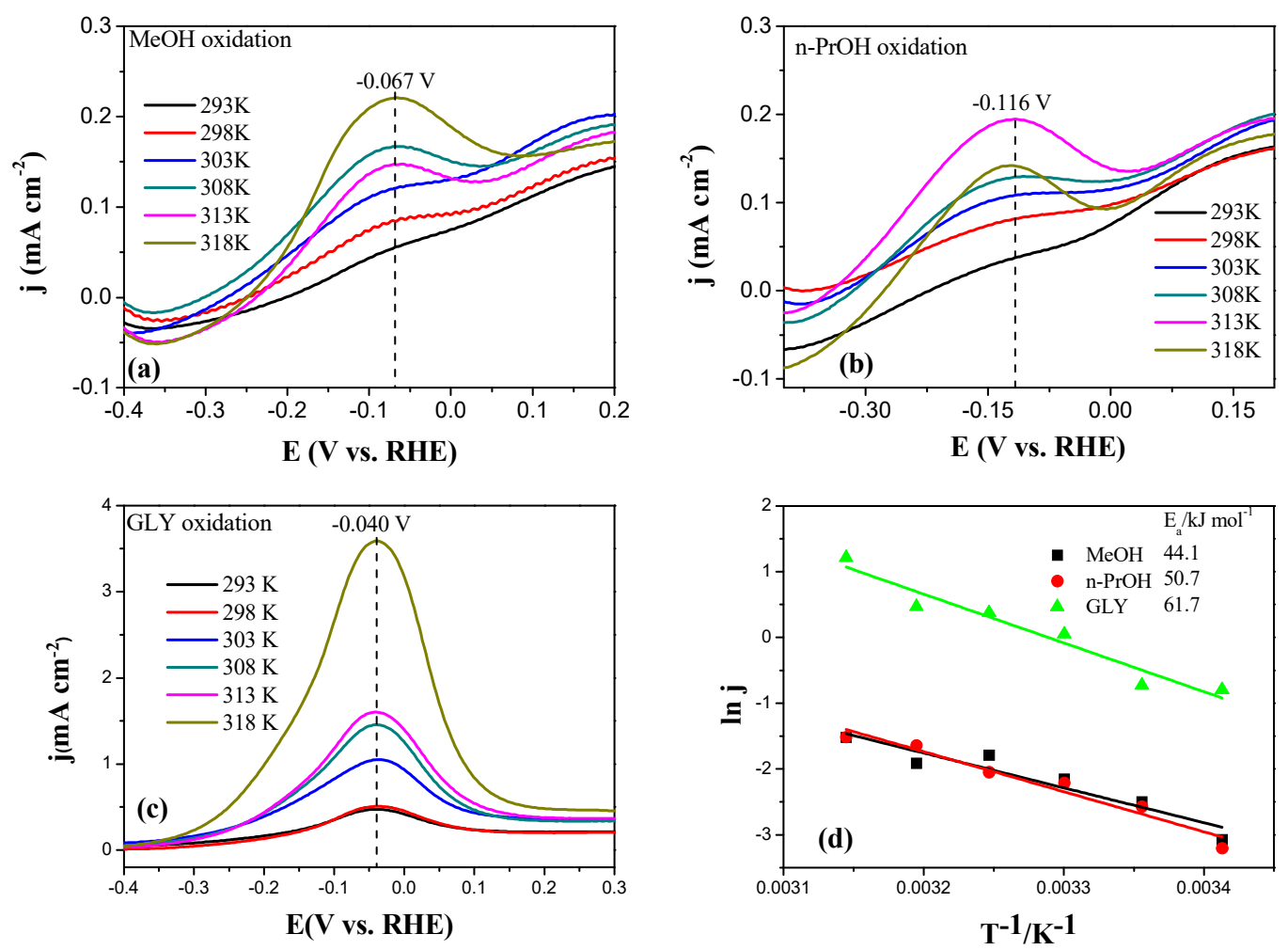

Figure 14. (a-c) LSVs of Pt electrode in $0.1 \mathrm{M} \mathrm{KOH}+0.025 \mathrm{M}$ alcohol; (d) Arrhenius plot of alcohol eletro-oxidation on $\mathrm{Pt}$ at peak potentials.

\section{Experimental}

\subsection{Materials and Reagents}

Carbon-nanotubes (CNTs) (>50 nm outer diameter, 5-15 nm inner diameter, 1-5 um length) were purchased from Chengdu Organic Chemicals Co. Ltd., Chinese Academy of Sciences (Chengdu, China). Methanol ( $\geq 99.5 \%)$, ethanol $(\geq 99.7 \%)$, and perchloric acid $(70-72 \%)$ were obtained from Sinopharm Chemical Reagent Co. Ltd (Shanghai, China). Ethylene glycol (EG, >99\%), n-propanol ( $\geq 99.9 \%)$, 2-propanol ( $\geq 99.9 \%$ ), glycerol (GLY, $\geq 99.5 \%)$, sodium borohydride $\left(\mathrm{NaBH}_{4}, 98 \%\right)$, cupric sulfate anhydrous $\left(\mathrm{CuSO}_{4}, 99 \%\right)$, potassium hydroxide $(\mathrm{KOH}, 95 \%)$, and potassium sulfate $\left(\mathrm{K}_{2} \mathrm{SO}_{4}\right.$, ACS) were obtained from Aladdin (Shanghai, China). Chloroplatinic acid hexahydrate $\left(\mathrm{H}_{2} \mathrm{PtCl}_{6} 6 \mathrm{H}_{2} \mathrm{O}\right.$, ACS reagent, $\geq 37.50 \% \mathrm{Pt}$ basis), palladium (II) chloride ( $\mathrm{PdCl}_{2}$, anhydrous, $60 \% \mathrm{Pd}$ basis), gold (III) chloride trihydrate $\left(\mathrm{HAuCl}_{4} \cdot 3 \mathrm{H}_{2} \mathrm{O}, \mathrm{ACS}\right.$ reagent, $\geq 49.0 \%$ Au basis), and poly (vinyl alcohol) (PVA, MW $=10,000,80 \%$ hydrolyzed) were obtained from Sigma-Aldrich (Shanghai, China).

\subsection{Catalyst Synthesis and Physical Characterizations}

Platinum was deposited on the carbon nanotubes (Nitric acid pretreated) by ethylene glycol reduction [47]. The amount of platinum precursor added was calculated to obtain a load of $1 \mathrm{wt} . \%$ $\mathrm{Pt} / \mathrm{CNTs}$ in the catalyst. EG was both a solvent and a reducing agent in this preparation. A solution of $\mathrm{H}_{2} \mathrm{PtCl}_{6} 3.2 \mathrm{mmol} \cdot \mathrm{L}^{-1}$ was prepared from high purity reagent and ethylene glycol. First, the precursor solution was slowly added to a dispersion of CNTs in EG under sonication and, afterwards, the $\mathrm{pH}$ of the dispersion was adjusted by adding an appropriate amount of $\mathrm{KOH}$ solution. The dispersion was stirred under reflux at $140^{\circ} \mathrm{C}$ for $2 \mathrm{~h}$. Subsequently, the catalyst was filtered and thoroughly washed with ultrapure water (with a resistivity of $18.2 \mathrm{M} \Omega \mathrm{cm}$ at $20^{\circ} \mathrm{C}$ ), and then dried in vacuo for $12 \mathrm{~h}$ at $70{ }^{\circ} \mathrm{C}$.

Pd nanoparticles were deposited on CNTs by a colloid method for a total metal concentration of $1 \mathrm{wt} . \%$ [48]. For the preparation of supported Pd colloidal materials, an aqueous solution of $\mathrm{PdCl}_{2}$ of 
the desired concentration was prepared. An aqueous solution of $\mathrm{NaBH}_{4}$ was used as the reduction agent. Fresh solutions of PVA were also prepared, as the stabilizing agent. First, to an aqueous $\mathrm{PdCl}_{2}$ solution of the desired concentration, the required amount of a PVA solution was added (vinyl alcohol $/ \mathrm{Pd}(\mathrm{mol} / \mathrm{mol})=1.2)$. A freshly prepared solution of $\mathrm{NaBH}_{4}\left(\mathrm{NaBH}_{4} / \mathrm{Pd}(\mathrm{mol} / \mathrm{mol})=20\right)$ was then added to form a colloid. After stirring for $30 \mathrm{~min}$, the colloid was immobilized by adding CNTs under vigorous stirring conditions. Lastly, the catalyst was filtered and thoroughly washed with $95^{\circ} \mathrm{C}$ hot ultrapure water, and then dried in vacuum for $12 \mathrm{~h}$ at $70^{\circ} \mathrm{C}$. The same steps were used to prepare $\mathrm{Au} / \mathrm{CNTs}$, but the amount of $\mathrm{NaBH}_{4}$ and PVA was changed and the corresponding precursor was used.

X-ray diffraction (XRD) analyses of the catalysts were performed using a Bruker AXS D8 Advanced Focus diffractometric using an $\mathrm{Ni}$ filtered $\mathrm{Cu} \mathrm{K} \alpha$ radiation under a $0.154 \mathrm{~nm} k$-value, and operated at $40 \mathrm{kV}$ and $40 \mathrm{~mA}$. Transmission electron microscopy (TEM, JEM-2100Plus) analysis was carried out by dispersing the powder products as slurry in ethanol before drying them on a $\mathrm{Cu}$ grid. Inductively coupled plasma atomic emission spectroscopy (ICP-AES, AA6800, Shimadzu, Japan) was used to determine the metal loading amounts on the carbon support. X-ray photoelectron spectra were obtained from an ESCALAB MKII spectrometer (VG Scientific, Waltham, MA, USA) using Al KR radiation. Spectra correction was based on adventitious carbon, using a $C 1$ s binding energy of $284.6 \mathrm{eV}$.

\subsection{Fabrication and Electrochemical Characterization of Electrodes}

Electrochemical experiments were carried out in an electrocatalytic three-electrode reactor using an Autolab PGSTAT 302N Potentiostat-Galvanostat (Shanghai, China) at room temperature.

Underpotential deposition (UPD) of copper was used to characterize high-surface-area electrocatalysts [49]. A Pt tablet and $\mathrm{Ag} / \mathrm{AgCl}$ (in $3 \mathrm{M} \mathrm{KCl}$ ) were used as the counter and reference electrodes, respectively. A rotating disk electrode (RDE, diameter $5 \mathrm{~mm}$ ) coated with catalyst was used as the working electrode. A catalytic ink was prepared from the metal/CNTs powder ( $2 \mathrm{mg}$ ) added in a mixture of $925 \mu \mathrm{L}$ of a water and ethanol (1:1) mixture and $75 \mu \mathrm{L}$ of Nafion (0.5 wt.\% from DuPont). Twenty $\mu \mathrm{L}$ of the catalytic ink was finally deposited onto each face of the carbon sheet and the solvent was evaporated at room temperature; this amount represents $0.0204 \mu \mathrm{g} \mathrm{cm}{ }^{2}$ of the metal loading. The cyclic voltammetry experiments were performed using a disk electrode rotated at $2000 \mathrm{rpm}$. The electrolyte was saturated with $\mathrm{N}_{2}$ at room temperature. All copper upd experiments were carried out in a $0.5 \mathrm{M} \mathrm{H}_{2} \mathrm{SO}_{4}$ and $0.001 \mathrm{M} \mathrm{CuSO}_{4}$ solution unless otherwise stated. A cyclic voltammetry scan was then performed from the admission potential to a point at which all of the upd copper was oxidized at a scan rate of $0.1 \mathrm{~V} \cdot \mathrm{s}^{-1}$.

The electro-oxidation of alcohols was carried out as above unless otherwise stated. In an alkaline environment, cyclic voltammetrys of different alcohols' oxidation were carried out in $50 \mathrm{~mL} 0.1 \mathrm{M} \mathrm{KOH}$ solution containing $1.25 \mathrm{mmol}$ alcohol at a sweep rate of $100 \mathrm{mV} \cdot \mathrm{s}^{-1}$. In an acidic environment, the supporting electrolyte was replaced with $0.1 \mathrm{M} \mathrm{HClO}_{4}$. In a neutral environment, it was replaced with $0.05 \mathrm{M} \mathrm{K}_{2} \mathrm{SO}_{4}$. The onset potential of a CV peak was determined by a derivative method. As shown in Figure 8 a point was found at which the derivative of the current density with respect to the potential was positive. The potential corresponding to this point is the onset potential.

\subsection{Apparent Activation Energy of Electrodes}

Electrochemical experiments were carried out in an electrocatalytic three-electrode reactor using an Autolab PGSTAT 302N Potentiostat-Galvanostat at room temperature. Solutions were freshly prepared and purged with high purity nitrogen before each experiment. A Pt tablet and a saturated calomel electrode were used as the counter and reference electrodes, respectively. A commercially available metal electrode was used as the working electrode, and linear scanning was performed at a series of temperatures. 


\section{Conclusions}

By investigating the electro-oxidation behaviors of some typical alcohols over $\mathrm{Pt}, \mathrm{Pd}$, and $\mathrm{Au}$ electrodes in acidic, neutral, and alkaline media, respectively, several regularities were discovered. Firstly, the acid-base property of the electrolyte media was a dominating influence for the catalytic activity of all these electrodes. Alkaline media as found to be the best, then acidic media. Alcohols were the most difficult to oxidize in neutral media, and thus had the lowest current density. Except for a few special cases, the onset potentials of the oxidation peak in alkaline media were about $0.6 \mathrm{~V}$ lower than that in acidic and neutral media. Secondly, Pt electrodes showed the best activities on the oxidation of most alcohols in all media, excepting for ethanol and n-propanol in alkaline media. Finally, the molecular structure distinction and hydrogen bond donation ability (HBD) of different alcohols were also found to have a great relationship with the catalytic performance. In alkaline media, on $\mathrm{Pt}$ electrodes, methanol with the highest HBD was more easily oxidized than other alcohols with low HBD. Contrarily, on Pd and Au electrodes, n-propanol with the lowest HBD was more easily oxidized compared to other alcohols. The case of Pt catalysts in acidic and neutral media was similar to that of $\mathrm{Pd}$ and $\mathrm{Au}$ in alkaline medium. The reasons of these regularities are still being explored. We hope that the results of this work will have guiding significance for the study of DAFCs in the future.

Author Contributions: Conceptualization, C.Z. and H.Y.; Methodology, B.W.; Software, Y.J.; Validation, Y.C., F.Y. and B.W.; Formal Analysis, B.W., and L.T.; Investigation, L.T.; Resources, Y.Y.; Data Curation, B.W.; Writing-Original Draft Preparation, B.W., and L.T.; Writing-Review \& Editing, C.Z., and H.Y.; Visualization, Y.J.; Supervision, C.Z.; Project Administration, Y.Y.; Funding Acquisition, C.Z.

Funding: This research was funded by [China National Natural Science Foundation] grant number [21503187].

Conflicts of Interest: The authors declare no conflict of interest.

\section{References}

1. Ye, J.; Liu, J.; Xu, C.; Jiang, S.; Tong, Y. Electrooxidation of 2-propanol on Pt, Pd and Au in alkaline medium. Electrochem. Commun. 2007, 9, 2760-2763. [CrossRef]

2. Winter, M.; Brodd, R.J. What Are Batteries, Fuel Cells, and Supercapacitors? Chem. Rev. 2004, 104, 4245-4269. [CrossRef] [PubMed]

3. Xin, L.; Zhang, Z.; Wang, Z.; Li, W. Simultaneous Generation of Mesoxalic Acid and Electricity from Glycerol on a Gold Anode Catalyst in Anion-Exchange Membrane Fuel Cells. ChemCatChem 2012, 4, 1105-1114. [CrossRef]

4. Zhang, Z.; Xin, L.; Sun, K.; Li, W. Pd-Ni electrocatalysts for efficient ethanol oxidation reaction in alkaline electrolyte. J. Hydrogen Energy 2011, 36, 12686-12697. [CrossRef]

5. Zalineeva, A.; Serov, A.; Padilla, M.; Martinez, U.; Artyushkova, K.; Baranton, S.; Coutanceau, C.; Atanassov, P.B. Self-supported $\mathrm{Pd}_{\mathrm{x}} \mathrm{Bi}$ catalysts for the electrooxidation of glycerol in alkaline media. J. Am. Chem. Soc. 2014, 136, 3937-3945. [CrossRef]

6. Benipal, N.; Qi, J.; Liu, Q.; Li, W. Carbon nanotube supported PdAg nanoparticles for electrocatalytic oxidation of glycerol in anion exchange membrane fuel cells. Appl. Catal. B Environ. 2017, 210, 121-130. [CrossRef]

7. Steele, B.C.H.; Heinzel, A. Materials for fuel-cell technologies. Nature 2001, 414, 345-352. [CrossRef]

8. Carreue, L.; Friedrich, K.A.; Stimming, U. Fuel Cells-Fundamentals and Applications. Fuel Cells 2015, 1, 5-39. [CrossRef]

9. Berger, D.J. Fuel Cells and Precious-Metal Catalysts. Science 1999, 286, 49. [CrossRef]

10. Luo, J.; Maye, M.M.; Kariuki, N.N.; Wang, L.; Njoki, P.; Lin, Y.; Schadt, M.; Naslund, H.R.; Zhong, C.-J. Electrocatalytic oxidation of methanol: Carbon-supported gold-platinum nanoparticle catalysts prepared by two-phase protocol. Catal. Today 2005, 99, 291-297. [CrossRef]

11. Samant, P.V.; Fernandes, J.B.; Rangel, C.M.; Figueiredo, J.L. Carbon xerogel supported Pt and Pt-Ni catalysts for electro-oxidation of methanol in basic medium. Catal. Today 2005, 102-103, 173-176. [CrossRef]

12. Zhang, X.; Tsang, K.-Y.; Chan, K.-Y. Electrocatalytic properties of supported platinum-cobalt nanoparticles with uniform and controlled composition. J. Electroanal. Chem. 2004, 573, 1-9. [CrossRef] 
13. Kadirgan, F.; Beden, B.; Leger, J.M.; Lamy, C. Synergistic effect in the electrocatalytic oxidation of methanol on platinum+palladium alloy electrodes. J. Electroanal. Chem. 1981, 125, 89-103. [CrossRef]

14. Horacio, R.C.; Ernesto, R.G. Direct Alcohol Fuel Cells; Springer: Dordrecht, The Netherlands, 2014; pp. 33-81, ISBN 978-94-007-7707-1.

15. Camara, G.A.; de Lima, R.B.; Iwasita, T. Catalysis of ethanol electrooxidation by PtRu: The influence of catalyst composition. Electrochem. Commun. 2004, 6, 812-815. [CrossRef]

16. Shen, P.K.; Xu, C. Alcohol oxidation on nanocrystalline oxide Pd/C promoted electrocatalysts. Electrochem. Commun. 2006, 8, 184-188. [CrossRef]

17. Xu, C.; Cheng, L.; Shen, P.; Liu, Y. Methanol and ethanol electrooxidation on Pt and Pd supported on carbon microspheres in alkaline media. Electrochem. Commun. 2007, 9, 997-1001. [CrossRef]

18. Bianchini, C.; Shen, P.K. Palladium-Based Electrocatalysts for Alcohol Oxidation in Half Cells and in Direct Alcohol Fuel Cells. Chem. Rev. 2009, 109, 4183-4206. [CrossRef] [PubMed]

19. Kwon, Y.; Schouten, K.J.P.; Koper, M.T.M. Mechanism of the Catalytic Oxidation of Glycerol on Polycrystalline Gold and Platinum Electrodes. ChemCatChem 2011, 3, 1176-1185. [CrossRef]

20. Simões, M.; Baranton, S.; Coutanceau, C. Electrochemical Valorisation of Glycerol. ChemSusChem 2012, 55, 2106-2124. [CrossRef] [PubMed]

21. Nishimura, K.; Kunimatsu, K.; Enyo, M. Electrocatalysis on Pd + Au alloy electrodes: Part III. IR spectroscopic studies on the surface species derived from $\mathrm{CO}$ and $\mathrm{CH}_{3} \mathrm{OH}$ in $\mathrm{NaOH}$ solution. J. Electroanal. Chem. 1989, 260, 167-179. [CrossRef]

22. Xu, C.; Tian, Z.; Chen, Z.; Jiang, S.P. Pd/C promoted by Au for 2-propanol electrooxidation in alkaline media. Electrochem. Commun. 2008, 10, 246-249. [CrossRef]

23. Antolini, E.; Gonzalez, E.R. Alkaline direct alcohol fuel cells. J. Power Sources 2010, 195, 3431-3450. [CrossRef]

24. Ago, H.; Kugler, T.; Cacialli, F.; Salaneck, W.R.; Shaffer, M.S.P.; Windle, A.H.; Friend, R.H. Work Functions and Surface Functional Groups of Multiwall Carbon Nanotubes. J. Phys. Chem. B 1999, 103, 8116-8121. [CrossRef]

25. Yu, H.; Jin, Y.; Peng, F.; Wang, H.; Yang, J. Kinetically controlled side-wall functionalization of carbon nanotubes by nitric acid oxidation. J. Phys. Chem. C 2008, 112, 6758-6763. [CrossRef]

26. Beden, B.; Çetin, I.; Kahyaoglu, A.; Takky, D.; Lamy, C. Electrocatalytic oxidation of saturated oxygenated compounds on gold electrodes. J. Catal. 1987, 104, 37-46. [CrossRef]

27. Rieger, P.H. Electrochemistry; Springer: Dordrecht, The Netherlands, 1994; pp. 187-198. [CrossRef]

28. Parker, V.D.; Tilset, M. Rapid, low activation energy, selective, direct reactions of cation radicals with nucleophiles. An experimental test of theory. J. Am. Chem. Soc. 1987, 109, 2521-2523. [CrossRef]

29. Marcus, Y. The Properties of Organic Liquids that are Relevant to their Use as Solvating Solvents. Chem. Soc. Rev. 1993, 22, 409-416. [CrossRef]

30. Pan, Z.F.; Chen, R.; An, L.; Li, Y.S. Alkaline anion exchange membrane fuel cells for cogeneration of electricity and valuable chemicals. J. Power Sources 2017, 365, 430-445. [CrossRef]

31. Li, M.; Liu, P.; Adzic, R.R. Platinum monolayer electrocatalysts for anodic oxidation of alcohols. J. Phys. Chem. Lett. 2012, 3, 3480-3485. [CrossRef]

32. Ozoemena, K.I.; Chen, S. Nanomaterials for Fuel Cell Catalysis; Springer: Dordrecht, The Netherlands, 2016; pp. 479-486. [CrossRef]

33. Li, N.; Zhou, Q.; Tian, S.; Zhao, H.; Li, X.; Adkins, J.; Gu, Z.; Zhao, L.; Zheng, J. Electrocatalytic oxidation of alcohols on single gold particles in highly ordered $\mathrm{SiO}_{2}$ cavities. Electrochim. Acta 2013, 109, 546-553. [CrossRef]

34. Michaelides, A.; Ranea, V.A.; de Andres, P.L.; King, D.A. General model for water monomer adsorption on close-packed transition and noble metal surfaces. Phys. Rev. Lett. 2003, 90, 216102-1-216102-4. [CrossRef]

35. Costa-Amaral, R.; Da Silva, J.L. The adsorption of alcohols on strained Pt3Ni(111) substrates: A density functional investigation within the D3 van der Waals correctiont. Phys. Chem. Chem. Phys. 2018, 20, 24210-24221. [CrossRef]

36. Schennach, R.; Eichler, A.; Rendulic, K.D. Adsorption and Desorption of Methanol on Pd (111) and on a Pd/V Surface Alloy. J. Phys. Chem. B 2003, 107, 2552-2558. [CrossRef]

37. Wang, L.; He, C.Z.; Zhang, W.H.; Li, Z.Y.; Yang, J.L. Methanol-selective oxidation pathways on Au surfaces: A first-principles study. J. Phys. Chem. C 2014, 118, 17511-17520. [CrossRef] 
38. Xu, Z.F.; Wang, Y.X. Effects of alloyed metal on the catalysis activity of $\mathrm{Pt}$ for ethanol partial oxidation: Adsorption and dehydrogenation on Pt3M (M = Pt, Ru, Sn, Re, Rh, And Pd). J. Phys. Chem. C 2011, 115, 20565-20571. [CrossRef]

39. Sheng, T.; Lin, W.F.; Hardacre, C.; Hu, P. Role of water and adsorbed hydroxyls on ethanol electrochemistry on Pd: New mechanism, active centers, and energetics for direct ethanol fuel cell running in alkaline medium. J. Phys. Chem. C 2014, 118, 5762-5772. [CrossRef]

40. Freire, R.L.; Kiejna, A.; Da Silva, J.L. Adsorption of water and ethanol on noble and transition-metal substrates: A density functional investigation within van der Waals corrections. Phys. Chem. Chem. Phys. 2016, 18, 29526-29536. [CrossRef]

41. Iwasita, T.; Nart, F.C.; Vielstich, W. An FTIR Study of the Catalytic Activity of a 85: 15 Pt: Ru Alloy for Methanol Oxidation. Phys. Chem. 1990, 94, 1030-1034. [CrossRef]

42. Pandey, R.K.; Lakshminarayanan, V. Ethanol electrocatalysis on gold and conducting polymer nanocomposites: A study of the kinetic parameters. Appl. Catal. B Environ. 2012, 125, 271-281. [CrossRef]

43. Jia, C.; Yin, H.M.; Ma, R.Y.; Ge, X.B.; Zhou, A.Q.; Xu, X.H.; Ding, Y. Enhanced photoelectrocatalytic activity of methanol oxidation on $\mathrm{TiO}_{2}$-decorated nanoporous gold. J. Phys. Chem. C 2009, 113, 16138-16143. [CrossRef]

44. Gupta, S.S.; Datta, J. A comparative study on ethanol oxidation behavior at Pt and PtRh electrodeposits. J. Electroanal. Chem. 2006, 594, 65-72. [CrossRef]

45. Su, Y.Z.; Xu, C.W.; Liu, J.P.; Liu, Z.Q. Electrooxidation of 2-propanol compared ethanol on Pd electrode in alkaline medium. J. Power Sources 2009, 194, 295-297. [CrossRef]

46. Liang, Z.X.; Zhao, T.S.; Xu, J.B.; Zhu, L.D. Mechanism study of the ethanol oxidation reaction on palladium in alkaline media. Electrochim. Acta 2009, 54, 2203-2208. [CrossRef]

47. Roychowdhury, C.; Matsumoto, F.; Mutolo, P.F.; Abruna, H.D.; DiSalvo, F.J. Synthesis, Characterization, and Electrocatalytic Activity of PtBi Nanoparticles Prepared by the Polyol Process. Chem. Mater. 2005, 17, 5871-5876. [CrossRef]

48. Lopez-Sanchez, J.A.; Dimitratos, N.; Hammond, C.; Brett, G.L.; Kesavan, L.; White, S.; Miedziak, P.; Tiruvalam, R.; Jenkins, R.L.; Carley, A.F.; et al. Facile removal of stabilizer-ligands from supported gold nanoparticles. Nat. Chem. 2011, 3, 551-556. [CrossRef] [PubMed]

49. Green, C.L.; Kucernak, A. Determination of the Platinum and Ruthenium Surface Areas in Platinum-Ruthenium Alloy Electrocatalysts by Underpotential Deposition of Copper. I. Unsupported Catalysts. J. Phys. Chem. B 2002, 106, 1036-1047. [CrossRef] 